\title{
Expression pattern of class I histone deacetylases in vulvar intraepithelial neoplasia and vulvar cancer: a tissue microarray study
}

\author{
Nicolas Samartzis ${ }^{1}$, Patrick Imesch ${ }^{1 *}$, Konstantin J Dedes ${ }^{1}$, Eleftherios P Samartzis ${ }^{1}$, André Fedier ${ }^{1}$, Daniel Fink , \\ Rosmarie Caduff ${ }^{2}$ and Mathias K Fehr ${ }^{3}$
}

\begin{abstract}
Background: Epigenetic regulation is an important mechanism leading to cancer initiation and promotion. Histone acetylation by histone deacetylases (HDACs) represents an important part of it. The development of HDAC inhibitors has identified the utility of HDACs as a therapeutic target. Little is known about the epigenetic regulation of vulvar intraepithelial neoplasia (VIN) and vulvar squamous cell cancer (VSCC). In this study, the expression of class I HDACs (HDAC 1, 2 and 3) was compared in a series of VIN and VSCC tissues.
\end{abstract}

Methods: A tissue micro array (TMA) with specimens from 106 patients with high-grade VIN and 59 patients with vulvar cancer was constructed. The expression of HDACs 1,2 and 3 were analyzed with immunohistochemistry $(\mathrm{IHC})$. The nuclear expression pattern was evaluated in terms of intensity and percentage of stained nuclei and was compared between vulvar preinvasive lesions and vulvar cancer.

Results: HDAC 2 expression was significantly higher in VIN than in VSCC ( $p<0.001$, Fisher's test). Also, 88.7\% ( $n=$ 94/106) of VIN samples and only 54.5\% $(n=31 / 57)$ of VSCC samples were scored at the maximum level.

Conversely, HDAC 3 expression was significantly higher in VSCC (93\%, 53/57) compared to VIN $(73.6 \%, 78 / 106, p=$ 0.003), whereas only a small difference in the expression of HDAC 1 was found between these two entities of vulvar neoplasia.

Conclusions: These results suggest that epigenetic regulation plays a considerable role in the transformation of VIN to invasive vulvar neoplasia.

Keywords: Histone deacetylase, epigenetics, vulvar intraepithelial neoplasia, vulvar squamous cell cancer, tissue microarray, immunohistochemistry

\section{Background}

Invasive vulvar squamous cell carcinomas (VSCC) represent the fourth most common type of malignant tumor of the female genital tract in the United States, with an estimated 3, 580 new cases and 900 deaths in 2009 [1]. Recently, a significant increase of precancerous lesions and invasive vulvar carcinomas has been observed in industrialized countries. The incidence of invasive and vulvar intraepithelial neoplasia (VIN) has risen $2.4 \%$ per year in the U.S. from 1992 to 1998 [2]. A Scandinavian

\footnotetext{
* Correspondence: Patrick.Imesch@usz.ch

'Department of Gynecology, University Hospital Zurich, Frauenklinikstrasse 10, 8091 Zurich, Switzerland

Full list of author information is available at the end of the article
}

study describes an increase in VIN incidence more than 4 times from 1973 to 2000 and of $20 \%$ for invasive vulvar cancer [3]. The described increase in incidence is seen primarily in younger women, whereas in elderly women, the incidence rates of vulvar cancer have remained relatively stable over the past few decades.

VIN is most commonly treated by local excision, laser evaporation, or a combination of both methods, to preserve vulvar function and morphology. The preferred treatment modality for VSCC is surgery whenever feasible. Small tumors are treated by wide local excision, with or without partial or radical vulvectomy, combined with lymph node staging via sentinel lymph node biopsy or inguinofemoral lymphadenectomy if lymph node

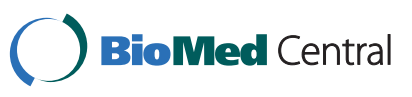


metastases are present. For patients with extensively involved inguinofemoral lymph nodes, radiotherapy of the pelvis is advantageous. For patients with recurrent or metastatic disease, irradiation and chemotherapy offer some benefit; however, response rates are regarded as low $[4,5]$. Targeted therapies for VSCC have not yet been established in clinical practice [6], but given the low benefit of conventional chemotherapies, novel systemic treatment modalities are urgently needed for these patients.

Epigenetics characterize the hereditary changes in the pattern of gene expression that are not due to changes in DNA sequence. Genetics and epigenetics interact at all stages of cancer development. Epigenetic alterations in mammalian genomes fall into two main categories: DNA methylation and histone modification. Histones are strongly alkaline proteins that are able to package the DNA and condense it into structural units called nucleosomes. Acetylation and deacetylation of histones are performed by histone acetyltransferase (HATs) and histone deacetylases (HDACs), respectively. HDACs increase the affinity of histone complexes to DNA. The chromatin is thereby more condensed and transcriptionally repressed [7-9].

Additionally HDACs can modify proteins other than histones, such as transcription factors (e.g. p53, E2F, $\mathrm{pRb}$ ). Acetylation can also affect protein stability and protein-protein interactions. Therefore, HDACs are emerging as important regulators of cell growth, differentiation, and apoptosis $[10,11]$. There are at least eighteen deacetylase enzymes known in human cells, categorized into four classes: class I (HDAC 1, 2, 3, 8), class II (HDAC 4, 5, 6, 7, 9, 10), class III (SIRT 1-7) and class IV (HDAC 11). HDAC1 and HDAC2 are one of the bestcharacterized HDACs. However, the isoenzyme-specific biological functions of HDACs are still mostly unknown [8]. It has been postulated that dysregulated function of HDACs leads to cancer formation and development [11]. Altered HDAC expression is observed in a variety of cancer types, such as prostate adenocarcinoma [12], gastric carcinoma [13], colorectal carcinoma [14], cervical dysplasia and endometrial stromal sarcoma [15]. In vulvar intraepithelial neoplasia and vulvar cancer, no data on HDAC expression has been published.

The aim of this study was to analyze the expression of the class I HDACs 1, 2 and 3 by immunohistochemistry in a series of VIN and VSCC samples using the tissue microarray technique and to correlate the finding with the clinicopathological features of the patients.

\section{Methods}

Patient characteristics

One-hundred-six patients diagnosed with high-grade VIN and 59 patients with VSCC between 1993 and 2006 at the Institute of Pathology, University Hospital Zurich were included in this study. The study was approved by the local ethics committee (ref. number StV 08/2006). Histological diagnosis was established according to the guidelines of the International Society for the Study of Vulvovaginal Disease (ISSVD) [16].

Clinical data were available for 158 of the 165 cases. Follow-up data of at least six months were available for 74 of the 106 patients with VIN and 25 of the 59 patients with VSCC. Mean follow-up time was 67.8 months ( $\mathrm{SD} \pm 41.8$, range $8-169$ months) and 50.6 months ( $\mathrm{SD} \pm 42.7$, range $6-149$ months) in patients with VIN and VSCCs, respectively. Table 1 shows the patient's age and p16 status in VIN and VSCC. Table 2 shows the clinicopathological data of the patients with VSCC included in the study.

\section{Tissue Microarray construction}

Two tissue microarrays (TMA), one for the VIN and one for the VSCC cases, were constructed using a semiautomatic tissue arrayer (Beecher Instruments, Woodland, USA) as previously described [17]. Areas involving vulvar cancer or VIN were marked on hematoxylin/ eosin-stained sections. Cylindrical cores $0.6 \mathrm{~mm}$ in diameter were punched out of the corresponding paraffin embedded block and inserted into a recipient block. Two different spots from each tumor were punched out.

\section{Immunohistochemistry}

TMA sections $(2.5 \mu \mathrm{m})$ were transferred to glass slides, followed by immunohistochemical analysis according to the Ventana automat protocols. The following antibodies were used: polyclonal rabbit IgG antibody against HDAC 1 (dilution 1:2, Abcam Limited, clone: ab15316, UK-CB4 OFL Cambridge, United Kingdom), monoclonal mouse IgG antibody against HDAC 2 (dilution 1:1000, Abcam Limited, clone: ab12169, UK-CB4 OFL Cambridge, United Kingdom) and monoclonal mouse IgG antibody against HDAC 3 (dilution 1:500, Becton Dickinson, clone: 611125, NJ-07417 Franklin Lakes, United States of America).

Additionally, immunohistochemical staining with p16 (dilution 1:200, Santa Cruz Biotechnology, clone: sc56330, CA-95060 Santa Cruz, United States of America)

Table 1 Patients' age and p16 status in different diagnostic groups

\begin{tabular}{cccccc}
\hline & p16 & $\mathbf{n}$ & age mean & SD & range \\
\hline \multirow{2}{*}{ VIN } & pos & 93 & 49.1 & \pm 14.6 & $22-89$ \\
& Neg & 13 & 74.3 & \pm 14.9 & $35-93$ \\
\multirow{2}{*}{ VSCC } & Pos & 31 & 61.8 & \pm 14.3 & $37-90$ \\
& Neg & 26 & 77.3 & \pm 10.3 & $53-93$ \\
\hline
\end{tabular}

Mean age, standard deviation (SD) and range are given in years. 
Table 2 Clinicopathological features of patients with vSCC

\begin{tabular}{lcc}
\hline \multicolumn{1}{l}{$\mathbf{n}$} & percentage \\
\hline T stage & 22 & $37.3 \%$ \\
1 & 24 & $40.7 \%$ \\
2 & 9 & $15.3 \%$ \\
3 & 0 & $0.0 \%$ \\
4 & 4 & $6.8 \%$ \\
Not available & & \\
Lymphe node metasases & 24 & $40.7 \%$ \\
None & 14 & $23.7 \%$ \\
Unilateral & 6 & $10.2 \%$ \\
Bilateral & 15 & $25.4 \%$ \\
Not available & & \\
Distant metastases & 28 & $47.5 \%$ \\
No & 1 & $1.7 \%$ \\
Yes & 30 & $50.8 \%$ \\
Not available & & \\
FIGO & 16 & $27.1 \%$ \\
I & 12 & $20.3 \%$ \\
II & 13 & $22.1 \%$ \\
III & 5 & $9.5 \%$ \\
IV & 13 & $22.0 \%$ \\
Not available & & \\
Tumor differentiation & 13 & $50.8 \%$ \\
Well & $30.0 \%$ \\
Moderate & 16 & \\
Poor & & \\
\hline
\end{tabular}

and Ki-67 (dilution 1:20, DAKO, clone: M7240, DK2600 Glostrup, Denmark) was performed.

P16, a tumor suppressor gene, inhibits cyclin dependent kinase 4 (CDK4), 6 (CDK6) and retinoblastoma protein $(\mathrm{pRb})$ and subsequently blocks the passage from G1 into $\mathrm{S}$ phase [18]. Human papilloma virus (HPV) inactivates p53 and pRb with its E6 and E7 oncogenic proteins after infection of epithelial cells, which results in an overexpression of p16 versus a negative feedback control of pRb $[19,20]$. Therefore, p16 expression has been established as a surrogate marker for HPV infection and is used for pathomorphological investigation [21-23]. Ki-67 (Mib-1) is expressed during cellular proliferation and, therefore, is used as a marker to determine the growth fraction in tissue samples (proliferation index) [24].

Immunohistochemical staining of HDAC isoforms was scored by applying a semiquantitative immunoreactivity scoring system (IRS). Therefore the percentage of positive cells was categorized as none (0), less then $10 \%$ of the cells (1), $10-50 \%$ of the cells (2), $51-80 \%$ of the cells (3), and more then $80 \%$ of the cells (4). The intensity was graded as absent (0), weakly positive $(1+)$, moderately positive $(2$ $+)$ or strongly positive $(3+)$. The IRS score results from multiplying the area-score with the intensity of immunoreactivity, as described elsewhere [25]. It ranges from 0 to 12 . Nuclear staining of HDACs was considered positive, whereas cytoplasmic staining was regarded as nonspecific. Both TMAs were scored by two observers (N. S. \& R.C.) who were blinded to the clinicopathological information of each sample. The two cores of each individual tumor were scored separately, and the mean score of the two twin tissue cores was attributed to a single patient.

To assess correlations and associations between expression of HDACs and clinicopathological parameters, Spearman's rho (bivariate correlation analysis), Fisher's exact test and $\chi$-square tests were applied, where appropriate. $\mathrm{p}$-values of $<0.05$ were considered significant. SPSS 18.0 package software (SPSS Inc., Chicago/Illinois, USA) was used.

\section{Results HDAC expression in VIN and VSCC}

Nuclear HDAC 1, 2 and 3 staining could be evaluated in 163 of 165 cases (98.8\%). In 9 cases out of 163 (5.5\%), only one of both tissue cores could be analyzed. In the non-evaluable cases, the cores lacked sufficient epithelial cells.

In VIN, mean IRS-scores of HDAC 1, HDAC 2 and HDAC 3 were 9.99, 11.56 and 10.88, and they were 9.83, 9.75 and 11.72 in VSCC, respectively. The median IRS-score was 12 for every HDAC isoform in both VIN as well as VSCC. Hence, the cut-off point for statistical analysis was taken at a score level of 12 . Results were, therefore, dichotomized into a "HDAC high" group (IRS = 12) and a "HDAC low" group (IRS < 12).

The Association of HDAC 1, 2 and 3 expressions with clinicopathological parameters is summarized in Table 3. HDAC 2 expression was significantly higher in VIN than in VSCC ( $\mathrm{p}<0.001$, Fisher's test). 88.7\% ( $\mathrm{n}=94 / 106)$ of VIN samples were scored at the maximum level (IRS 12); vulvar cancer samples only in $54.5 \%(n=31 / 57)$. Conversely, HDAC 3 expression was significantly higher in VSCC $(93 \%, 53 / 57)$ compared to VIN $(73.6 \%, 78 / 106)$, and $\mathrm{p}=0.003$. No significant distribution was found for HDAC 1 within vulvar neoplasias. In fact, the percentage of tissue samples with high HDAC 1 protein expression is almost equal between VIN (57.5\%) and VSCC (56.1\%). The reciprocal expression pattern of HDAC 2 and 3 is illustrated in representative tissue examples in Figure 1 and graphically visualized in Figure 2.

In a bivariate correlation analysis, IRS scores of the three HDAC isoforms correlated significantly with each other in VIN samples, whereas no correlation between isoform 2 and 3 was found in VSCC.

\section{Correlation of HDAC expression with clinicopathological parameters}

There was a moderate correlation between HDAC 2 and $\mathrm{pT}$ stage in $\operatorname{VSCC}(\mathrm{p}=0.009)$, whereas no 
Table 3 Association of HDACs with clinicopathological parameters

\begin{tabular}{|c|c|c|c|c|c|c|c|c|c|c|}
\hline & Total & HDAC1 low & HDAC1 high & $p$ & HDAC2 low & HDAC2 high & $p$ & HDAC3 low & HDAC3 high & $p$ \\
\hline All Cases & 163 & 70 (42.9\%) & $93(57.1 \%)$ & - & 38 (23.3\%) & $125(76.7 \%)$ & - & $32(19.6 \%)$ & $131(80.4 \%)$ & - \\
\hline VIN & 106 & $45(42.5 \%)$ & $61(57.5 \%)$ & 0.87 & $12(11.3 \%)$ & 94 (88.7\%) & $<0.001$ & $28(26.4 \%)$ & 78 (73.6\%) & 0.003 \\
\hline VSCC & 57 & $25(43.9 \%$ & $32(56.1 \%)$ & & $26(45.6 \%)$ & 31 (54.4\%) & & $4(7.0 \%)$ & $53(93.0 \%)$ & \\
\hline p16 neg & 39 & $17(43.6 \%)$ & $22(56.4 \%)$ & 1.00 & $10(25.6 \%)$ & 29 (74.4\%) & 0.67 & $4(10.3 \%)$ & 35 (89.7\%) & 0.109 \\
\hline p16 pos & 124 & $53(42.7 \%)$ & 71 (57.3\%) & & $28(22.6 \%)$ & 96 (77.4\%) & & $28(22.6 \%)$ & $96(77.4 \%)$ & \\
\hline Age $\leq 60$ & 93 & 41 (44.1\%) & $52(55.9 \%)$ & 0.752 & $22(23.7 \%)$ & 71 (76.3\%) & 1.00 & $21(22.6 \%)$ & 72 (77.4\%) & 0.322 \\
\hline Age $>60$ & 70 & $29(41.4 \%)$ & $41(58.6 \%)$ & & 16 (22.9\%) & $54(77.1 \%)$ & & $11(15.7 \%)$ & 59 (84.3\%) & \\
\hline \multicolumn{11}{|l|}{$\mathrm{VSCC}^{\circ}$} \\
\hline pT1 & 20 & 7 (35.0\%) & $13(65.0 \%)$ & $0.556^{*}$ & $5(25.0 \%)$ & $15(75.0 \%)$ & $0.057^{*}$ & $1(5.0 \%)$ & 19 (95.0\%) & $0.831^{*}$ \\
\hline pT2 & 24 & $11(45.8 \%)$ & $13(54.2 \%)$ & & $13(54.2 \%)$ & $11(45.8 \%)$ & & $2(8.3 \%)$ & $22(91.7 \%)$ & \\
\hline pT3 & 9 & $5(55.6 \%)$ & $4(44.4 \%)$ & & $6(66.7 \%)$ & $3(33.3 \%)$ & & 1 (11.1\%) & 8 (88.9\%) & \\
\hline pNO & 23 & 9 (39.1\%) & 14 (60.9\%) & 0.763 & 9 (39.1\%) & $14(60.9 \%)$ & 0.366 & $1(4.3 \%)$ & $22(95.7 \%)$ & 1.00 \\
\hline $\mathrm{pN} 1 / 2$ & 20 & $9(45.0 \%)$ & $11(55.0 \%)$ & & $11(55.0 \%)$ & $9(45.0 \%)$ & & 1 (5.0\%) & 19 (95.0\%) & \\
\hline G1 & 12 & $5(41.7 \%)$ & 7 (58.3\%) & $0.009^{*}$ & 7 (58.3\%) & $5(41.7 \%)$ & $0.602^{*}$ & $1(8.3 \%)$ & 11 (91.7\%) & $0.513^{*}$ \\
\hline G2 & 29 & $8(27.6 \%)$ & 21 (72.4\%) & & 12 (41.4\%) & 17 (58.6\%) & & $1(3.4 \%)$ & $28(96.6 \%)$ & \\
\hline G3 & 16 & $12(75 \%)$ & $4(25.0 \%)$ & & 7 (43.8\%) & 9 (56.3\%) & & $2(12.5 \%)$ & $14(87.5 \%)$ & \\
\hline \multicolumn{11}{|l|}{ VIN } \\
\hline $\mathrm{Ki}-67 \leq 10 \%$ & 11 & $9(81 \%)$ & $2(18.2 \%)$ & 0.008 & $3(27.3 \%)$ & $8(72.7 \%)$ & 0.109 & $4(36.4 \%)$ & 7 (63.6\%) & 0.476 \\
\hline Ki-67 > 10\% & 95 & 36 (37.9\%) & 59 (62.1\%) & & 9 (9.5\%) & 86 (90.5\%) & & $24(25.3 \%)$ & 71 (74.7\%) & \\
\hline \multicolumn{11}{|l|}{ vscC } \\
\hline $\mathrm{Ki}-67 \leq 10 \%$ & 19 & $8(42.1 \%)$ & 11 (57.9\%) & 1.00 & $14(73.7 \%)$ & $5(26.3 \%)$ & 0.004 & $2(10.5 \%)$ & 17 (89.5\%) & 0.594 \\
\hline Ki-67 > 10\% & 38 & 17 (44.7\%) & $21(55.3 \%)$ & & $12(31.6 \%)$ & $26(68.4 \%)$ & & $2(5.3 \%)$ & $36(94.7 \%)$ & \\
\hline
\end{tabular}

HDAC immunoreactivity score (IRS) has been dichotomized in two groups; HDAC 1 to 3 "high" represent tissue samples with a IRS of 12 , HDAC 1 to 3 "Iow", a IRS less than 12. Clinicopathological parameters investigated in this study are listed in the first column; Vulvar intraepithelial neoplasia (VIN), vulvar squamous cell cancer (VSCC); p-16 as a surrogate marker for human papilloma virus (HPV) infection as described before [21-23]; patient younger than 60 years (Age $\leq 60$ ), patient equal or elder than 60 years (Age > 60); related pTNM-stage and tissue differentiation (G1 to G3) in VSCC. Nuclear Ki-67 protein is a marker for cell proliferation. "Ki- $67 \leq 10 \%$ " means that 10 percent or less of the cells are proliferating.

Percentages in parentheses are according to the total number of samples in the first column. P-values result from the association of HDAC low and high groups to one parameter, such as tissue type VIN versus VSCC. Where not specified, Fisher's exact test was used to calculate p-values. P-values labeled by * have been obtained by $\chi$-square test. For a facilitated reading, corresponding data to $p$-values are in one grid each.

- T-stage: 6 cases missing at all, no cases of pT4; N-stage: 15 cases missing; M-stage: not shown, 30 cases with no investigation and or data missing.

significant association between tumor size and high HDAC 2 expression was observed. A high proliferation index (Ki-67 area) correlated with high HDAC $1(\mathrm{p}=$ $0.008, \mathrm{cc}=0.21)$ and HDAC $2(\mathrm{p}<0.001, \mathrm{cc}=0.36)$ expression. Using cut-off levels of $10 \%$, this correlation was confirmed (Table 3). Similar to this findings, applying a cut-off level of $25 \%$ results in a significant associations between Ki-67 and HDAC 1 in VIN ( $\mathrm{p}=$ 0.012 ) and Ki-67 and HDAC 2 in the VSCC group (p $=0.035$ ).

In the grouped analyses, no significant association between p16 positivity and patient age with HDAC expression was observed (Table 3). In fact, almost equal frequencies were found between p16 and HDAC 1 as well as between patient age and HDAC 2. There was no significant association between tumor size (pT) and high HDAC 2 expression.

\section{Discussion}

This study shows that class I HDACs are highly expressed in the majority of VIN and VSCC; however, the expression patterns differ between VIN and VSCC. High HDAC-2 protein expression is found more often in VIN, and high HDAC-3 protein expression is found more often in VSCC. These two types of HDACs are neither associated with patient age nor with level of p16 expression. Therefore, the observed differences are not explained by the difference of the average age or frequency of p16 positivity in VIN and VSCC. The immunohistochemical staining showed high intensity in the majority of tissue samples, and negative results were not found. HDAC 3 was the most intensely expressed isoform of all three class I HDACs.

Based on the expression pattern of histone deacetylating proteins, we hypothesized that epigenetic regulation plays a major role in the pathogenesis of invasive vulvar cancer, as has been demonstrated for several other malignancies [12-15]. The transformation of non-invasive to invasive vulvar neoplasia may be promoted by epigenetic regulation. To our knowledge, this report is the first on class I HDAC expression in vulvar cancer or vulvar intraepithelial neoplasia. 

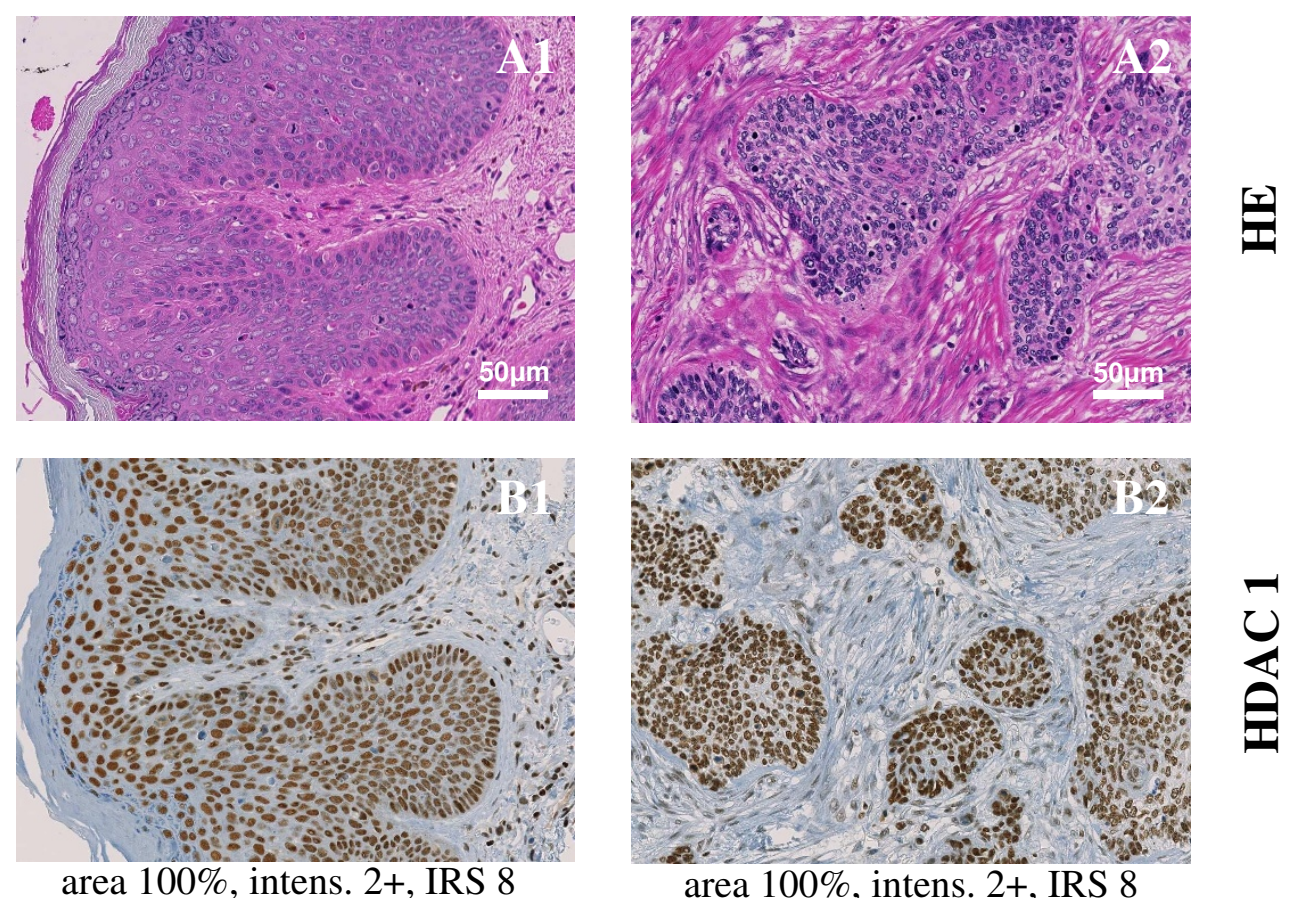

II

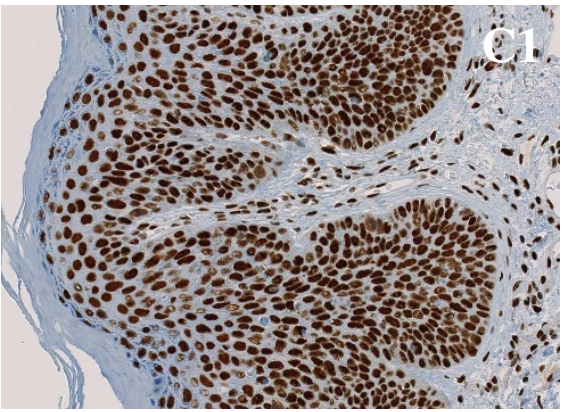
area $100 \%$, intens. $2+$, IRS 8
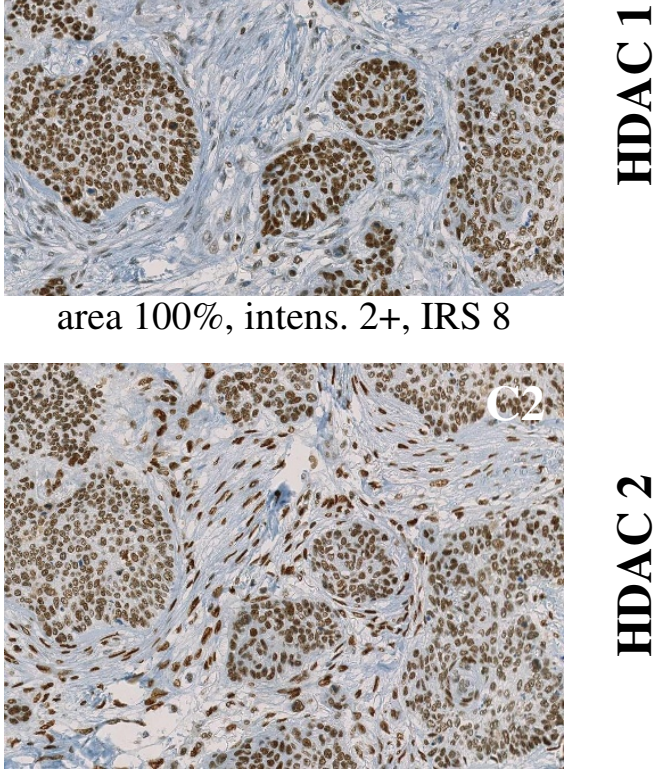

area $100 \%$, intens. $3+$, IRS 12

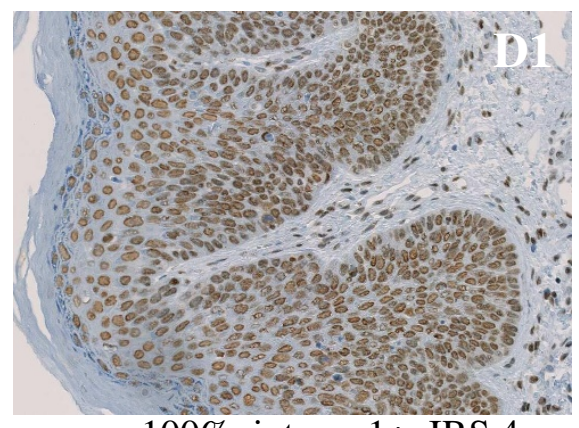

area $100 \%$, intens. $1+$, IRS 4

\section{VIN}

$\sum^{N}$

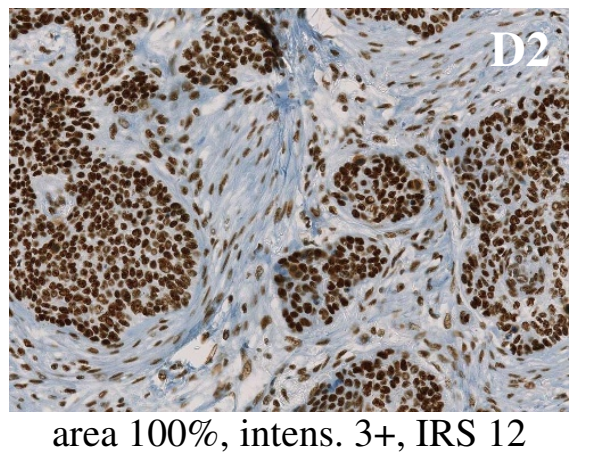

area $100 \%$, intens. $1+$, IRS 4

\section{VSCC}

Figure 1 Representative tissue samples of one VIN microarray core (A1, B1, C1, D1) and one VSCC microarray core (A2, B2, C2, D2) stained with hematoxylin/eosin (HE) (A1 and A2) and nuclear immunohistochemical reaction with class I HDAC antibodies: HDAC 1 (B1 and B2), HDAC 2 (C1 and C2) and HDAC 3 (D1 and D2); Magnification $\times 200$. Under each immunohistochemical stain, the percentage of positive epithelial cells within the tissue core (area), the intensity of immunoreactions (intens.) and the immunoreactivity score (IRS) are indicated. 


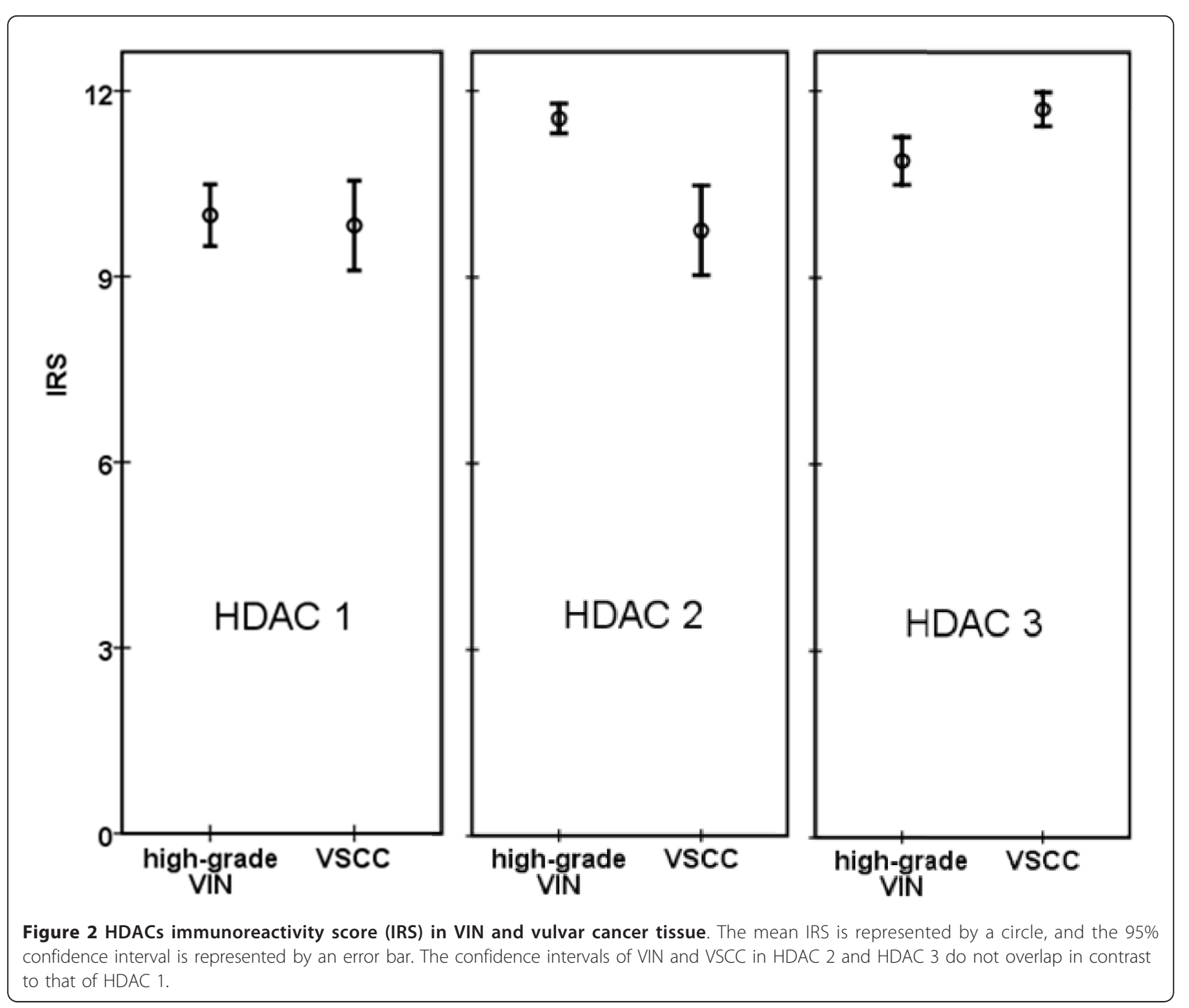

P16 has been proposed as a surrogate marker for HPV associated neoplasia [21-23]. We found no difference between class I HDAC expression in p16-negative or p16-positive tumor tissue. Therefore, the regulation of gene expression by HDACs seems to be independent of $\mathrm{HPV}$ infection.

One mechanism by which HDACs appear to stimulate tumor cell growth is through the repression of the tumor suppressor gene, p21 [26]. In this study, high expression of HDAC 1 in VIN and high expression of HDAC 2 in VSCC were associated with increased cell proliferation, as defined by Ki-67. This result supports previous findings in other tumor types, such as prostate cancer and colorectal cancer [27,28]. With the exception of the significant correlation of HADC 1 and 2 with the proliferation marker $\mathrm{Ki}-67$, no relation was found between HDAC expression and clinicopathological features. Still, the utility of these results must be considered carefully because of the lack of a full clinical data set.

The epigenetic regulation of HDACs has recently been explored as a therapeutic target by the discovery and development of HDAC-inhibitors (HDACi). In-vitro data suggest that HDACi induce cell cycle arrest, differentiation, and apoptosis [15,29-32]. The antitumor effects of HDACi emphasize the important role of HDACs in cancer development. However, HDACi affects the activity of several enzymes, and it is difficult to identify the particular functions of different HDAC isoforms involved in cancerogenesis. Several HDACi are currently under clinical investigation involving various hematological malignancies and solid tumors, of which vorinostat has already been approved for the systemic treatment of cutaneous T cell lymphoma [33]. Particularly, in oral squamous cell cancer, there are different phase I and II trials using HDAC-i as a monotherapy or in 
combination with other agents. This treatment method is of interest regarding VSCC [34-37].

\section{Conclusions}

In summary, HDACs, the targets of HDACi, are highly expressed in the majority of VIN and VSCC and show a different expression pattern among these two tissue types irrespective of the HPV-related etiology. Investigations of HDAC-i for the topical or systemic treatment of VIN and VSCC are warranted.

\section{Acknowledgements}

This study was supported by grants from the Research Foundation of the University of Zurich. For technical support, we wish to thank Mrs. M. Storz and Mrs. S. Behnke. All statistics were verified by the Division of Biostatistics, University of Zurich.

Part of this paper was presented at the annual meeting of the Swiss Gynecological Society (SGGG) meeting 2010 in Interlaken, Switzerland.

\section{Author details}

${ }^{1}$ Department of Gynecology, University Hospital Zurich, Frauenklinikstrasse 10, 8091 Zurich, Switzerland. 'Department of Pathology, University Hospital Zurich, Schmelzbergstrasse 12, 8091 Zurich, Switzerland. ${ }^{3}$ Department of Gynecology and Obstetrics, Hospital of Frauenfeld, 8051 Frauenfeld, Switzerland.

\section{Authors' contributions}

NS constructed the tissue microarray (TMA), scored the immunohistochemical (IHC) staining and drafted the manuscript. PI prepared the study design, interpreted data and drafted part of the manuscript. KJD evaluated the patients for study inclusion and contributed to the conclusion section of the manuscript. EPS performed statistical analyses and drafted part of the result section. AF contributed to the interpretation of data and developed figures for the manuscript. DF assisted with the interpretation of data and contributed to the draft of the manuscript. RC revised diagnosis of the paraffin embedded tissue samples and analyzed the IHC-staining of the two TMAs. MFK conceived the study, collected data and coordinated the procedures during this study. All authors read and approved the final manuscript.

\section{Competing interests}

The authors declare that they have no competing interests.

Received: 28 January 2011 Accepted: 26 October 2011

Published: 26 October 2011

\section{References}

1. Jemal A, Siegel R, Ward E, Hao Y, Xu J, Thun MJ: Cancer statistics, 2009. CA Cancer J Clin 2009, 59(4):225-249.

2. Howe HL, Wingo PA, Thun MJ, Ries LA, Rosenberg HM, Feigal EG, Edwards BK: Annual report to the nation on the status of cancer (1973 through 1998), featuring cancers with recent increasing trends. J Natl Cancer Inst 2001, 93(11):824-842.

3. Judson PL, Habermann EB, Baxter NN, Durham SB, Virnig BA: Trends in the incidence of invasive and in situ vulvar carcinoma. Obstet Gynecol 2006, 107(5):1018-1022.

4. Moore $\mathrm{DH}$ : Chemotherapy and radiation therapy in the treatment of squamous cell carcinoma of the vulva: Are two therapies better than one? Gynecol Oncol 2009, 113(3):379-383.

5. Ghurani GB, Penalver MA: An update on vulvar cancer. Am J Obstet Gynecol 2001, 185(2):294-299.

6. Manchana T, Ittiwut C, Mutirangura A, Kavanagh JJ: Targeted therapies for rare gynaecological cancers. Lancet Oncol 11(7):685-693.

7. Bernstein BE, Meissner A, Lander ES: The mammalian epigenome. Cell 2007, 128(4):669-681.

8. Jones PA, Baylin SB: The epigenomics of cancer. Cell 2007, 128(4):683-692.
9. Kouzarides T: Chromatin modifications and their function. Cell 2007, 128(4):693-705.

10. Glozak MA, Rogers MB: Retinoic acid- and bone morphogenetic protein 4-induced apoptosis in P19 embryonal carcinoma cells requires p27. Exp Cell Res 2001, 268(2):128-138.

11. Glozak MA, Seto E: Histone deacetylases and cancer. Oncogene 2007 26(37):5420-5432.

12. Halkidou K, Gaughan L, Cook S, Leung HY, Neal DE, Robson CN: Upregulation and nuclear recruitment of HDAC1 in hormone refractory prostate cancer. Prostate 2004, 59(2):177-189.

13. Song J, Noh JH, Lee JH, Eun JW, Ahn YM, Kim SY, Lee SH, Park WS, Yoo NJ, Lee $J Y$, et al: Increased expression of histone deacetylase 2 is found in human gastric cancer. APMIS 2005, 113(4):264-268.

14. Huang BH, Laban M, Leung CH, Lee L, Lee CK, Salto-Tellez M, Raju GC, Hooi SC: Inhibition of histone deacetylase 2 increases apoptosis and p21Cip1/WAF1 expression, independent of histone deacetylase 1. Cell Death Differ 2005, 12(4):395-404.

15. Hrzenjak A, Moinfar F, Kremser ML, Strohmeier B, Staber PB, Zatloukal K, Denk H: Valproate inhibition of histone deacetylase 2 affects differentiation and decreases proliferation of endometrial stromal sarcoma cells. Mol Cancer Ther 2006, 5(9):2203-2210.

16. Sideri M, Jones RW, Wilkinson EJ, Preti M, Heller DS, Scurry J, Haefner H, Neill S: Squamous vulvar intraepithelial neoplasia: 2004 modified terminology, ISSVD Vulvar Oncology Subcommittee. J Reprod Med 2005, 50(11):807-810.

17. Kononen J, Bubendorf $L$, Kallioniemi A, Barlund M, Schraml P, Leighton S, Torhorst J, Mihatsch MJ, Sauter G, Kallioniemi OP: Tissue microarrays for high-throughput molecular profiling of tumor specimens. Nat Med 1998, 4(7):844-847.

18. Sano T, Oyama T, Kashiwabara K, Fukuda T, Nakajima T: Immunohistochemical overexpression of p16 protein associated with intact retinoblastoma protein expression in cervical cancer and cervical intraepithelial neoplasia. Pathol Int 1998, 48(8):580-585.

19. Santos M, Montagut C, Mellado B, Garcia A, Ramon y Cajal S, Cardesa A, Puig-Tintore LM, Ordi J: Immunohistochemical staining for p16 and p53 in premalignant and malignant epithelial lesions of the vulva. Int $J$ Gynecol Pathol 2004, 23(3):206-214.

20. Riethdorf S, Neffen EF, Cviko A, Loning T, Crum CP, Riethdorf L: p16INK4A expression as biomarker for HPV 16-related vulvar neoplasias. Hum Pathol 2004, 35(12):1477-1483.

21. Santos M, Landolfi S, Olivella A, Lloveras B, Klaustermeier J, Suarez H, Alos L, Puig-Tintore LM, Campo E, Ordi J: p16 overexpression identifies HPVpositive vulvar squamous cell carcinomas. Am J Surg Pathol 2006, 30(11):1347-1356.

22. Biedermann $\mathrm{K}$, Dandachi N, Trattner M, Vogl G, Doppelmayr H, More $\mathrm{E}_{\text {, }}$ Staudach A, Dietze O, Hauser-Kronberger C: Comparison of real-time PCR signal-amplified in situ hybridization and conventional PCR for detection and quantification of human papillomavirus in archival cervical cancer tissue. J Clin Microbiol 2004, 42(8):3758-3765.

23. O'Neill CJ, McCluggage WG: $p 16$ expression in the female genital tract and its value in diagnosis. Adv Anat Pathol 2006, 13(1):8-15.

24. Scholzen T, Gerdes J: The Ki-67 protein: from the known and the unknown. J Cell Physiol 2000, 182(3):311-322.

25. Weichert W, Roske A, Gekeler V, Beckers T, Ebert MP, Pross M, Dietel M, Denkert C, Rocken C: Association of patterns of class I histone deacetylase expression with patient prognosis in gastric cancer: a retrospective analysis. Lancet Oncol 2008, 9(2):139-148.

26. Marks P, Rifkind RA, Richon VM, Breslow R, Miller T, Kelly WK: Histone deacetylases and cancer: causes and therapies. Nat Rev Cancer 2001, 1(3):194-202.

27. Weichert W, Roske A, Gekeler V, Beckers T, Stephan C, Jung K, Fritzsche FR, Niesporek S, Denkert C, Dietel M, et al: Histone deacetylases 1, 2 and 3 are highly expressed in prostate cancer and HDAC2 expression is associated with shorter PSA relapse time after radical prostatectomy. $\mathrm{Br}$ J Cancer 2008, 98(3):604-610.

28. Weichert W, Roske A, Niesporek S, Noske A, Buckendahl AC, Dietel M, Gekeler V, Boehm M, Beckers T, Denkert C: Class I histone deacetylase expression has independent prognostic impact in human colorectal cancer: specific role of class I histone deacetylases in vitro and in vivo. Clin Cancer Res 2008, 14(6):1669-1677. 
29. Munster PN, Troso-Sandoval T, Rosen N, Rifkind R, Marks PA, Richon VM: The histone deacetylase inhibitor suberoylanilide hydroxamic acid induces differentiation of human breast cancer cells. Cancer Res 2001 61(23):8492-8497.

30. Imesch P, Fink D, Fedier A: Romidepsin reduces histone deacetylase activity, induces acetylation of histones, inhibits proliferation, and activates apoptosis in immortalized epithelial endometriotic cells. Fertil Steril 2010.

31. Li X, Chen BD: Histone Deacetylase Inhibitor M344 Inhibits Cell Proliferation and Induces Apoptosis in Human THP-1 Leukemia Cells. Am J Biomed Sci 2009, 1(4):352-363.

32. Hrzenjak A, Moinfar F, Kremser ML, Strohmeier B, Petru E, Zatloukal K, Denk $\mathrm{H}$ : Histone deacetylase inhibitor vorinostat suppresses the growth of uterine sarcomas in vitro and in vivo. Mol Cancer 2010, 9:49.

33. Tan J, Cang S, Ma Y, Petrillo RL, Liu D: Novel histone deacetylase inhibitors in clinical trials as anti-cancer agents. $J$ Hematol Oncol 2010, 3:5.

34. Kim J, Guan J, Chang I, Chen X, Han D, Wang CY: PS-341 and histone deacetylase inhibitor synergistically induce apoptosis in head and neck squamous cell carcinoma cells. Mol Cancer Ther 9(7):1977-1984.

35. Shen J, Huang C, Jiang L, Gao F, Wang Z, Zhang Y, Bai J, Zhou H, Chen Q: Enhancement of cisplatin induced apoptosis by suberoylanilide hydroxamic acid in human oral squamous cell carcinoma cell lines. Biochem Pharmacol 2007, 73(12):1901-1909.

36. Chung YL, Lee MY, Pui NN: Epigenetic therapy using the histone deacetylase inhibitor for increasing therapeutic gain in oral cancer: prevention of radiation-induced oral mucositis and inhibition of chemical-induced oral carcinogenesis. Carcinogenesis 2009, 30(8):1387-1397.

37. Murakami J, Asaumi J, Kawai N, Tsujigiwa H, Yanagi Y, Nagatsuka H, Inoue T, Kokeguchi S, Kawasaki S, Kuroda M, et al: Effects of histone deacetylase inhibitor FR901228 on the expression level of telomerase reverse transcriptase in oral cancer. Cancer Chemother Pharmacol 2005, 56(1):22-28.

Pre-publication history

The pre-publication history for this paper can be accessed here: http://www.biomedcentral.com/1471-2407/11/463/prepub

doi:10.1186/1471-2407-11-463

Cite this article as: Samartzis et al:: Expression pattern of class I histone deacetylases in vulvar intraepithelial neoplasia and vulvar cancer: a tissue microarray study. BMC Cancer 2011 11:463.

\section{Submit your next manuscript to BioMed Central and take full advantage of:}

- Convenient online submission

- Thorough peer review

- No space constraints or color figure charges

- Immediate publication on acceptance

- Inclusion in PubMed, CAS, Scopus and Google Scholar

- Research which is freely available for redistribution

Submit your manuscript at www.biomedcentral.com/submit
Biomed Central 